\title{
Permanent First Molars Clinical Status among School Children Aged 8-12 Years in Kathmandu
}

\author{
Anju Khapung, ${ }^{1}$ G. Nagaraja Rao, ${ }^{2}$ Sujita Shrestha ${ }^{3}$ \\ ${ }^{1,3}$ Lecturer, ${ }^{2}$ Professor, Department of Community Dentistry, \\ ${ }^{1}$ Nepal Medical College, ${ }^{2,3}$ Kantipur Dental College, Kathmandu, Nepal.
}

\begin{abstract}
Introduction: Common oral diseases affecting school children are dental caries, gingivitis and malocclusion. Teeth mostly affected by dental caries in permanent dentition of children are the permanent first molars. Permanent first molars are key factors in occlusion and are most susceptible to dental caries. They maintain arch perimeter and provide best anchorage. Loss of these teeth leads to various problems like space management, tooth migration, problem in mastication and malocclusion.
\end{abstract}

Objective: To assess the clinical status of first permanent molars among 8-12 year school children of Kathmandu.

Methods: A cross-sectional study was done among 220 schoolchildren of age 8-12 years randomly selected from 2 private and 2 public schools of Kathmandu. Dental caries, gingival and oral hygiene status were measured by Decayed Missing Filled teeth (DMFT) index, Gingival index and Oral hygiene index-Simplified (OHI-S) respectively. Data was entered in Epidata 3.1 and analyzed in SPSS version 20.

Results: The prevalence of dental caries in first permanent molars for study population was 54.5\%. Mean DMFT score of first permanent molars was $0.96+1.2$. Out of 867 molars examined, 197 (22.7\%) were decayed. 98.5\% of molars were erupted. Among the total study population, $184(83.6 \%)$ had fair oral hygiene and $203(83 \%)$ had gingivitis.

Conclusions: This study shows the need to improve oral health status of first permanent molars of school children through promotion of dental health awareness and curative public health measures at school level.

Keywords: Dental caries, gingivitis, oral hygiene status, permanent first molars.

\section{INTRODUCTION}

Among common oral diseases like dental caries, gingivitis and malocclusion, ${ }^{1}$ the major one is dental caries affecting $60-90 \%$ of school children of the world. ${ }^{2}$ Mostly affected teeth due to dental caries in the permanent dentition of children are the permanent first molars, specifically in their occlusal surfaces. ${ }^{3,4}$

Permanent mandibular first molars are the first permanent

\section{Correspondence}

Dr. Anju Khapung

Lecturer, Department of Community Dentistry,

Nepal Medical College, Kathmandu, Nepal

E-mail: khapunganju@gmail.com

\section{Citation}

Khapung A, Rao G N, Shrestha S. Permanent First Molars Clinical Status among School Children Aged 8-12 Years in Kathmandu. J Nepal Assoc Pediatr Dent. 2020;1(1):8-12. teeth to erupt in the oral cavity followed by permanent maxillary first molars. They erupt distal to primary second molars and have no predecessor. The presence of deep pits and fissures also makes it difficult for these teeth to be kept plaque free. ${ }^{5}$ Being the first permanent teeth to erupt, they have the most susceptibility to caries attack. ${ }^{6}$

Permanent first molars are important as they bear maximum occlusal load, maintain arch perimeter, and provide the best anchorage. They serve as a key factor in occlusion and as growth centers and their presence influences vertical height of upper and lower jaws and other esthetic properties. ${ }^{7}$ Extraction or removal of these teeth leads to various problems in space management, tooth migration, mastication and proper occlusion. ${ }^{8}$

In the age group of 8-12 years old, first permanent molars will have already been erupted and exposed to oral environment for 2-6 years. So, these teeth may have been 
affected by various oral health problems like dental caries, gingivitis and poor oral hygiene in absence of preventive measures. Thus, this study attempts to assess the clinical status of permanent first molars among school children aged 8-12 years old of Kathmandu.

\section{METHODS}

A cross sectional descriptive study was conducted among 8-12 years old school children of Kathmandu district. Data collection was done from November 1st - 30th, 2017.

Sample size was calculated using the following formula:

$$
\text { Sample size }=z^{2} p q / d^{2}
$$

Taking the prevalence rate of dental caries as $85 \%$ from a study in Nepal, ${ }^{9}$ the calculated sample size was 204 (approx. 220). Four schools (2 public and 2 private) were selected by convenient sampling method and the school children of particular age group (8-12 years) were randomly selected and included in the study. The children who were medically compromised, absent on the day of examination and who refused to give consent to participate in the study were excluded from the study.

Ethical approval was taken from Institutional Review Committee (IRC) of Kantipur Dental College and Hospital prior to the study. Written permission for conducting the study was taken from the Principals of each of the schools and verbal consent was taken from each participant.

Data were collected and recorded in a pre-designed proforma comprising two parts: first part included demographic details and personal history while the second part included clinical examinations with selected standard indices. Dental caries, gingival and oral hygiene status were measured by Decayed Missing Filled Teeth

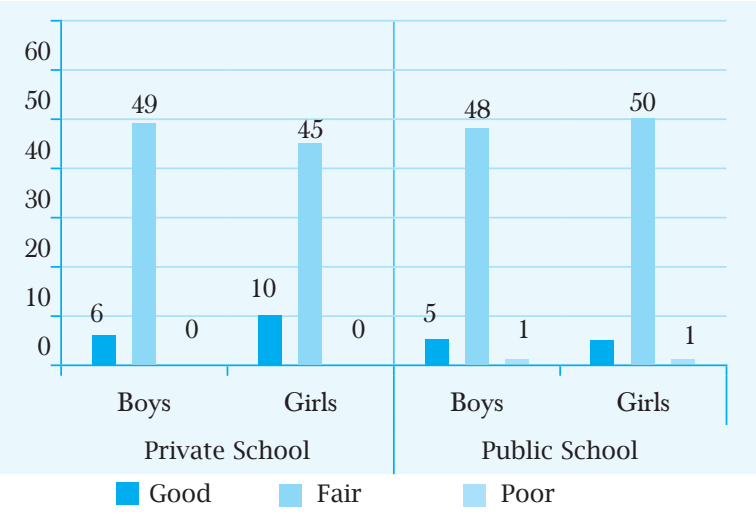

Figure 1: Distribution of study participants according to level of oral hygiene.
(DMFT) index, Gingival index and Oral hygiene indexSimplified (OHI-S) respectively. Intra-examiner reliability was tested by Kappa Coefficient among $22(10 \%$ of the sample) who were not included in the main study. Kappa value for DMFT, Gingival indices and OHI-S were, 0.80, 0.70 and 0.89 respectively. Only fully erupted permanent first molars were included in the study.

Examination was done using mouth mirror, probe and explorer under natural light. Aseptic measures were followed during the examination for infection control.Data was entered in Epidata version 3.1 and analyzed using statistical package for social sciences (SPSS version 20).

\section{RESULTS}

Out of the total 220 school children examined, 109 (49.5\%) were boys and 111 (50.5\%) were girls. Total number of students in private and public schools were taken as 110 in each group. The prevalence of dental caries in first permanent molars among the school children was 50\%, wherein caries prevalence among boys was $45.9 \%$ and among girls it was $54.1 \%$. Among this prevalence the private school children showed caries prevalence of $57.3 \%$ and it was $42.7 \%$ among the public school children. Of the total 880 permanent first molars examined, 13 (1.5\%) were partially erupted. Out of fully erupted 867 permanent first molars, 197 (22.7\%) were decayed. Mean DMFT score of the study population was 0.96 . There was no statistically significant difference in mean DMFT score according to gender-wise $(\mathrm{p}$-value $=0.24)$ and school type $(\mathrm{p}$-value $=$ 0.17) (Table 1).

Among the total study participants, majority 192 (87.3\%) had fair oral hygiene and only $2(0.9 \%)$ had poor oral hygiene. Majority of boys and girls from both the public and private schools had fair oral hygiene (Figure 1). Mean

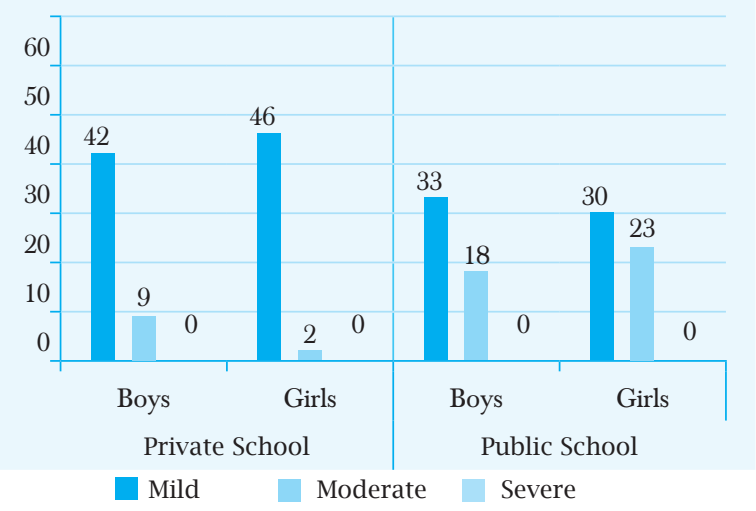

Figure 2: Distribution of study participants according to severity of gingivitis. 
Table 1: Mean DMFT in permanent first molars according to gender and type of school. Variables Decayed teeth Missing teeth Filled teeth Mean DMFT \pm S.D p-value

\begin{tabular}{|l|c|c|c|c|c|c|}
\hline & Boys & 87 & 3 & 4 & $0.86 \pm 1.18$ \\
\hline \multirow{2}{*}{ Gender } & Girls & 110 & 3 & 4 & $1.05 \pm 1.25$ & 0.24 \\
\hline & Total & 197 & 6 & 8 & $0.96 \pm 1.22$ \\
\hline \multirow{2}{*}{ Type of school } & Private & 106 & 4 & 8 & $1.07 \pm 1.22$ & 0.17 \\
\hline & Public & 91 & 2 & 0 & $0.85 \pm 1.21$ & \\
\hline
\end{tabular}

Independent t-test, p-value $<0.05$ statistically significant*

Table 2: Mean OHI-S score in permanent first molars according to gender and type of school.

\begin{tabular}{|c|c|c|c|c|c|c|}
\hline \multicolumn{2}{|c|}{ Variables } & $\begin{array}{c}\text { Good oral } \\
\text { hygiene }\end{array}$ & $\begin{array}{l}\text { Fair oral } \\
\text { hygiene }\end{array}$ & $\begin{array}{l}\text { Poor oral } \\
\text { hygiene }\end{array}$ & Mean OHI-S \pm S.D & $\mathrm{p}$-value \\
\hline \multirow{3}{*}{ Gender } & Boys & $11(10.1 \%)$ & $97(89 \%)$ & $1(0.9 \%)$ & $1.87 \pm 0.49$ & \multirow{3}{*}{0.07} \\
\hline & Girls & $15(13.5 \%)$ & 95 (85.6\%) & $1(0.9 \%)$ & $1.70 \pm 0.44$ & \\
\hline & Total & $26(11.8 \%)$ & $192(87.3 \%)$ & $2(0.9 \%)$ & $1.9 \pm 0.53$ & \\
\hline \multirow{3}{*}{ Type of school } & Private & $16(14.5 \%)$ & $94(85.5 \%)$ & $0(0 \%)$ & $1.79 \pm 0.48$ & \multirow{3}{*}{$<0.005^{\star}$} \\
\hline & Public & $10(9.1 \%)$ & $98(89.1 \%)$ & $2(1.8 \%)$ & $2.04 \pm 0.56$ & \\
\hline & Total & $26(11.8 \%)$ & $192(87.3 \%)$ & $2(0.9 \%)$ & $1.9 \pm 0.53$ & \\
\hline
\end{tabular}

Independent t-test, $p$-value $<0.05$ statistically significant

Table 3: Mean Gingival score in permanent first molars according to gender and type of school.

\begin{tabular}{|l|c|c|c|c|c|c|}
\hline \multicolumn{2}{|c|}{ Variables } & Mild gingivitis & $\begin{array}{c}\text { Moderate } \\
\text { gingivitis }\end{array}$ & $\begin{array}{c}\text { Mean gingival } \\
\text { score } \pm \text { S.D }\end{array}$ & Mean OHI-S \pm S.D & p-value \\
\hline \multirow{2}{*}{ Gender } & Boys & $75(73.5 \%)$ & $27(26.5 \%)$ & $2.26 \pm 0.44$ & $1.87 \pm 0.49$ \\
\hline & Girls & $76(75.2 \%)$ & $25(24.8 \%)$ & $2.25 \pm 0.43$ & $1.70 \pm 0.44$ & 0.78 \\
\cline { 2 - 6 } & Total & $151(74.4 \%)$ & $52(25.6 \%)$ & $2.26 \pm 0.44$ & $1.9 \pm 0.53$ & $1.79 \pm 0.48$ \\
\hline \multirow{2}{*}{ Type of school } & Private & $88(88.9 \%)$ & $11(11.1 \%)$ & $2.11 \pm 0.32$ & $2.04 \pm 0.56$ & $<0.05^{*}$ \\
\hline & Public & $63(60.6 \%)$ & $41(39.4 \%)$ & $2.39 \pm 0.49$ & $1.9 \pm 0.53$ \\
\hline
\end{tabular}

Independent t-test, p-value $<0.05$ statistically significant

OHI-S score of the study population was 1.9 and there was no statistically significant difference in mean OHI-S score according to gender ( $\mathrm{p}$-value $=0.07$ ). The public school children had greater OHI-S score than the private school children and this difference was found to be statistically significant ( $\mathrm{p}$-value < 0.005) (Table 2). 
Majority of the boys and girls from both public and private schools had mild gingivitis and none of them had severe gingivitis (Figure 2). About $92.3 \%$ of the participants had gingivitis of which 151 (74.4\%) had mild gingivitis and 52 (25.6\%) had moderate gingivitis. The difference in gingival score among public and private school children was not statistically significant $(\mathrm{p}$-value $=0.78)$. The public school children had greater gingival score than private school children and this difference was found to be statistically significant (p-value < 0.005) (Table 3).

\section{DISCUSSION}

The present study was conducted to assess the clinical status by dental caries, oral hygiene and gingival status of permanent first molars among 8-12 years old school children of Kathmandu. Only the permanent first molars were examined as they play a key role in predicting the dental health of an individual.

In this study, the dental caries prevalence was found to be $50 \%$. In studies conducted by Devaki et al. ${ }^{5}$ and Motta $\mathrm{LJ}$ et al. ${ }^{10}$ the dental caries prevalence were reported to be $47.4 \%$ and $38.6 \%$ respectively, values lower than the present study. A study done in Jeddah, by Al-Samadani $\mathrm{KH}$ et $\mathrm{al}^{11}$ reported caries prevalence of $75.5 \%$, a finding higher than the present research. This difference could be due to variations in study methodology, site, sample and socio-cultural factors.

In the current study the prevalence of dental caries of permanent first molars was lower among boys (45.9\%) than girls (54.1\%). This finding was in accordance with the finding by Abuaffan $\mathrm{AH}$ et al. ${ }^{12}$ in which the prevalence among boys and girls were found to be $39.9 \%$ and $60.1 \%$ respectively. The mean DMFT in present study was found to be 0.96 , a finding similar to the study by Chirca EM et al. ${ }^{13}$ who reported mean DMFT as 0.7. Studies done by Desai V et al. ${ }^{14}$ Taboada AO et al. ${ }^{15}$ and Sadeghi $\mathrm{M}^{16}$ reported mean DMFT to be $0.12,1.4$ and 1.9 respectively, which is in contrast to the present study.

The decayed component constituted the major portion with negligible filled component in the present study. This finding is in accordance with the study done by Khanal $\mathrm{S}$ et al. $^{9}$ This indicates low perceived treatment needs among people despite the availability of dental facilities. It may also be due to economic constraints among parents of public school children and lack of awareness among the parents of private school children.

Public school children exhibited higher DMFT than the private school children in studies conducted by Togoo RA et al. ${ }^{17}$ and Beiruti $\mathrm{N}$ et al. ${ }^{18}$ This finding was in contrast with the current study which showed that there was no statistically significant difference in mean DMFT among public and private school children.

In the current study, $87.3 \%$ of the school children had fair oral hygiene. This was higher as compared to a study by Srivastava et al. $^{8}$ who reported that $59.19 \%$ of the study participants had fair oral hygiene. No significant difference between sexes was found regarding mean oral hygiene score. However, there was statistically significant difference in mean oral hygiene score between private and public school children, where the public school children had a higher score. This shows that better oral hygiene status is present in private school children than in public school children.

The prevalence of gingivitis in the current study was found to be $92.3 \%$. which was higher than the findings of various studies by Motta LJ et al., ${ }^{10}$ Srivastava et al., ${ }^{8}$ and Singh M. et al. ${ }^{19}$ who reported prevalence of gingivitis to be $85.5 \%$, $50 \%$ and $78.35 \%$ among their study population respectively.

The absence of severe gingivitis among the study participants is in accordance with the finding that majority had fair oral hygiene. However, majority having gingivitis, though in mild form, reflects irregular brushing methods.

There was statistically significant difference in the mean gingival scores between private and public school children among which the public school children had a higher gingival score. This indicated better gingival health among private school children, attributing the study of having a lower oral hygiene score i.e. better oral hygiene among private school children. However, there was no significant difference in mean gingival score among male and female students.

\section{CONCLUSIONS}

This study presents the clinical status of permanent first molars among the school children and the need to improve the oral health status of first permanent molars of school children. This could be done through promotion of 
dental health awareness and implementation of preventive and curative public health measures at school level.

\section{ACKNOWLEDGEMENTS}

We would like to thank Dr. Sunita Khanal, Department of Community Dentistry, Kantipur Dental College, Kathmandu and Dr. Rosina Bhattarai, Department of
Community Dentistry, College of Medical Sciences, Bharatpur for their invaluable support.

Conflict of Interest: None

JNAPD

\section{REFERENCES}

1. Aparna M Thakur, Mala Dixit Baburaj (2015) Prevalence of Dental Health Problems among School going Children in Rural Areas of Thane District, Maharashtra. Int J Dentistry Oral Sci. 2(7), 106-110. [Full Text I DOI]

2. Petersen PE. The World Oral Health Report 2003: continuous improvement of oral health in the 21st century-the approach of the WHO Global Oral Health Programme. Community Dentistry and Oral Epidemiology. 2003 Dec;31(s1):3-24. [PubMed I DOI]

3. Bille J, Hesselgren K, Thylstrup A. Dental caries in Danish 7-, 11-and 13-year-old children in 1963, 1972 and 1981. Caries Research. 1986 Nov;20(6):534-42. [PubMed I DOI]

4. Larmas MA, Virtanen JI, Bloigu RS. Timing of first restorations in permanent teeth: a new system for oral health determination. Journal of Dentistry. 1995 Dec 1;23(6):347-52. [PubMed I DOI]

5. Devaki T. Permanent first molar caries status and treatment needs among school going children aged 6-14 years in Tenali, Guntur (DT)-A cross sectional study. Journal of Indian Association of Public Health Dentistry. 2011 Oct 1;9(18):455-461. [Full Text]

6. King NM, Shaw L, Murray JJ. Caries susceptibility of permanent first and second molars in children aged 5-15 years. Community Dentistry and Oral Epidemiology. 1980 Jun;8(3):151-8. [PubMed | DOI]

7. Arrow P. Prevalence of developmental enamel defects of the first permanent molars among school children in Western Australia. Australian Dental Journal. 2008 Sep;53(3):250-9. [PubMed I DOI]

8. Srivastava BK, Shetty NR, Varghese AG. Status of the First Permanent Molars among School Children of Bangalore City \{8-12 yrs\}. Journal of Indian Association of Public Health Dentistry. 2011 Jun 1;9(17):98-104. [Full Text]

9. Khanal S, Bhattarai R, Rao GN, Shrestha S. Prevalence of Dental Caries among Primary School Children of Kathmandu District-A Pilot Study. Journal of College of Medical Sciences-Nepal. 2017 Jul 17;13(2):275-8. [Full Text I DOI]

10. Motta LJ, Santos JG, Alfaya TA, Guedes CC, Godoy CHL, Bussadori SK. Clinical status of permanent first molars in children aged seven to ten years in a Brazilian rural community. Braz J Oral Sci. 2012; 11: 475-80. [Full Text]

11. Al-Samadani KH, Ahmad MS. Prevalence of first permanent molar caries in and its relationship to the dental knowledge of 9-12-year olds from Jeddah, kingdom of Saudi Arabia. IntSch Res Notices Dent. 2012;2012:1-6. [PubMed I DOI]

12. Abuaffan AH, Hayder S, Hussen AA, Ibrahim TA. Prevalence of dental caries of the first permanent molars among 6-14 years old Sudanese children. Indian Journal of Dental Education. 2018 Mar;11(1):13-6. [Full Text I DOI]

13. Chirca EM, Luca R, Georgescu DE. The prevalence of caries in First Permanent Molar in a group of school children aged 6 to 7 years in Pitesti. Proc Rom Acad. 2015; (Supplement 1):41-4. [Full Text]

14. Desai VC, Reddy RE, Manjula M, Saheb SH. Prevalence of dental caries in first and second permanent molars. Int J Res Med Sci 2014;2:514-20. [Full Text I DOI]

15. Taboada-Aranza O, Rodríguez-Nieto K. Prevalence of plaque and dental decay in the first permanent molar in a school population of south Mexico City. Boletin Medico del Hospital Infantil de Mexico. 2018 ;75(2):113-118. [PubMed I DOI]

16. Sadeghi M. Prevalence and bilateral occurrence of first permanent molar caries in 12-year-old students. J Dent Res Dent Clin Dent Prospects. 2007. Summer;1(2):86-92. [PubMed | DOI]

17. Togo RA, Yaseen SM, Zakirulla M, Al-Garni F, Khoraj AL, Meer A, et al. Prevalence of first permanent molar caries among 7-10 years old school going boys in Abha city, Saudi Arabia. J Int Oral Health. 2011;3:29-34. [Full Text]

18. Beiruti N, van Palenstein Helderman WH. Oral health in Syria. International Dental Journal. 2004 Dec; 54(6 Suppl 1): 383-8. [PubMed].

19. Singh M, Saini A, Saimbi CS, Bajpai AK. Prevalence of dental diseases in 5- to 14-year-old school children in rural areas of the Barabanki district, Uttar Pradesh, India. Indian J Dent Res 2011;22:396-9. [PubMed I DOI] 